\title{
Physical Activity Levels in Male and Female Diabetic Patients at the Pretoria Academic Hospital, South Africa
}

\begin{abstract}
Introduction: A comprehensive literature review indicated the existence of a gap in the studying of gender difference and physical activity in people with Diabetes Mellitus (DM) in South Africa.

Objectives: The aims of this study was to determine the level of physical activity (LPA) of diabetes patients of the Diabetes clinic of the Pretoria Academic Hospital (DCPAH), to compare the LPA between male and female diabetes patients and to explore the reasons for possible differences.

Design: A descriptive and comparative quantitative study.

Setting: Diabetes Clinic of the Pretoria Academic Hospital

Subjects: The convenience sample consisted of 65 subjects $(29$ males and

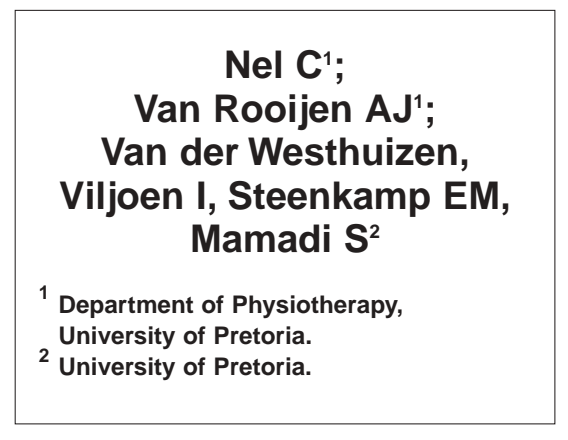
36 females) between the ages of 18 and 83 years

Results: The average physical activity of male subjects was 5164.05 METs compared to 4843.83 METs in female subjects. A p-value of 0.3660 was calculated. Of the subjects, 46,15\% achieved a high LPA, 27,69\% achieved a moderate LPA and 26.15\% achieved a low LPA according to the IPAQ scoring system. The seven main barriers found was health, diabetes, time, laziness, socio-economic circumstances, perceptual adequate exercise and other.

Conclusion: The overall LPA of diabetes patients is high according to the IPAQ Categorical scoring. The difference between LPA of males and females is not significant as indicated by the p-value ( $p>0.05)$. It was however found that males have higher levels of work related activities than females and that females have higher home and garden related activities than males. The two most frequently mentioned barriers for male and female subjects were time and health related conditions.
\end{abstract}

\section{KEY WORDS: DIABETES, PHYSICAL ACTIVITY, IPAQ, GENDER DIFFERENCES, AND BARRIERS.}

\section{INTRODUCTION}

Diabetes Mellitus (DM) is a metabolic disorder that has grown to gross numbers over the past few decades (URL: http://www.diabetessa.org [02 February 2007]). It has emerged as a major medical problem in developing countries including countries in Africa and has even been called an epidemic.

The estimated global occurrence of type 2 diabetes is predicted to rise by $25 \%$ in the next decade (URL: http: //www.diabetessa.org [02 February 2007]). In South 85 to $90 \%$ of diabetics have Type 2 Diabetes (URL: http://www. diabetessa.org [02 February 2007]).

\section{CORRESPONDENCE TO:}

Dr AJ van Rooijen

Department of Physiotherapy

University of Pretoria

Tel: (012) 354-2023

Fax: (012) 354-1226

E-mail: Tania.vrooijen@up.ac.za
DM means that either the body doesn't produce enough insulin, or cells are resistant against insulin produced, in order to lower blood sugar levels or to facilitate reuptake of glucose by body tissue (Motala et al 2003).

A variety of literature states that exercise improves glycaemic control, cardiovascular fitness and insulin sensitivity. Both aerobic exercise and strength training benefit glucose control (McArdle et al 2000, Bungard et al 1998, Seiler 1996).

Exercise physiology has been studied since approximately 480 B.C. and a great influence on the Western civilization came from the Greek physicians of antiquity. By the early nineteenth century, topics like diet and nutrition, information on exercise, how to develop overall fitness, personal health and hygiene, and training exercises for recreation became the most researched topics and still are today (McArdle et al 2000)

Exercise or physical activity also helps prevent diabetes. It is estimated that physical inactivity accounts for $24 \%$ of the risk to develop type 2 diabetes (Delahanty 2002). It has been proven that lifestyle interventions are comparable to structured exercise programs to improve fitness and decrease the risk for cardiovascular problems (Becker et al 2001).

There are a number of research studies that document gender-based differences in health, but very little on specific gender differences regarding diabetes. Such literature adds a lot of value in the scientific body of knowledge as it brings understanding in the way men and women are affected by illnesses, and thus their response to them and their treatment thereof.

The literature review indicated the existence of a gap in the studying of gender differences in physical activity in people with diabetes in South Africa.

In a study to determine the knowledge, attitudes and level of physical 
activity of black female patients with DM type 2 at the Mamelodi hospital, it was found that barriers for doing exercise should be determined before a physical activity program can be implemented (Van Rooijen et al 2001).

The research question for this study was: Is there a difference in the level of physical activity (LPA) between male and female diabetes patients and if so, why does it differ?

The objectives of the study are 1) to determine the LPA of diabetes patients; 2) To compare the LPA between male and female diabetes patients and 3) To explore the reasons for possible differences on the LPA between the two genders.

\section{METHODOLOGY}

Ethical clearance was obtained from the Student Research Ethics Committee of the Faculty of Health Sciences of the University of Pretoria. The Head of the Department of Epidemiology and the Diabetes Clinic and the CEO of the Pretoria Academic Hospital also gave their consent for the study.

\section{SUBJECTS}

A convenience sample of 65 subjects was used - 29 males and 36 females. All subjects were patients attending the Diabetes Clinic of Pretoria Academic Hospital for their usual follow-up visits. To be included in the study the subjects had to be older than 18 years of age, and had to give their written consent to participate in the study. The study allowed for subjects with type 1 or type $2 \mathrm{DM}$, any ethnic group, and any educational level. All subjects under the age of 18 were excluded as well as subjects who did not understand English or Afrikaans.

\section{METHODS}

The Diabetes Clinic is open everyday from Monday to Friday from $8 \mathrm{~h} 00$ in the morning until all patients scheduled for that day were seen. Patients arrive for their appointments early in the morning, blood and urine samples are taken, and while their test samples are being processed, they wait for the doctor to see them.

A pilot study was conducted before commencement of data collection, to determine duration per interview, whether subjects understood the questions and whether the right information is obtained to answer the research question. Four subjects were interviewed - two males and two females. Their results were included in the final data analysis.

Due to academic responsibilities of the researchers, data was collected on only 11 weekdays between the 5 th of May and the 8th of June 2006. On these days, subjects were recruited by introducing the study to them. The number of patients attending the clinic is limited due to limited clinic personnel and all patients did not consent to taking part in the study. Details of the study were fully explained including possible risks as well as benefits. It was made clear that they participate voluntarily and that they could withdraw at any stage without any penalty. Each subject received a signed copy of the consent form.

A one-on-one interview was performed with each subject in the language they preferred (Afrikaans or English). The research-interviewer wrote the answers down on the questionnaire, explaining each question to the subject beforehand if he/she did not understand.

Only four patients refused to take part. Three said they didn't feel like answering questions. One said he was there to get tested for diabetes so he didn't know if he had the condition yet.

\section{INSTRUMENTATION}

For this study, the IPAQ Long format was used. The questionnaire was revised in October 2002 and consists out of 27 items. It assesses specific types of activity of walking, moderate-intensity activities, and vigorous-intensity activities, which are undertaken in four domains. The domains include leisure time physical activity; domestic and gardening (yard) activities; work-related physical activity; and transport-related physical activity. Data collected with the IPAQ long format can be reported as median MET-minutes and/or given as one of three levels of physical activity such as 'low', 'moderate', and 'high' (www.ipaq.ki.se 2006).

The IPAQ has a section on household activities. This is important, because women will also be assessed and most women are involved in various household tasks.

The IPAQ allows comparisons between populations. A 12-country reliability and validity study considering whether this new instrument had acceptable measurement properties showed that $75 \%$ of test-retest correlations (in the 12 countries) were above 0.65 and that the overall estimation of physical activity by this questionnaire was correlated (Craig et al 2003).

Additional information was gained on the subjects' age, ethnic group, gender and highest educational level. Patients were asked which type of diabetes they have. If they didn't know, it was checked in their patient file.

An additional list of questions was asked on details of their exercise routine and perceived barriers preventing them from being more physically active than presently. The following questions were asked:

1. Do you think exercise is important for you? Why?

2. Does your condition (diabetes and/or its complications) prevent you from being employed if unemployed?

3. Do you do exercise/sport during leisure time? Describe training program.

4. Do you like doing exercise/sport?

5. Would you like to do more exercise/sport than currently? If yes: What prevents you from doing more? If no: Why don't you want to do more?

6. Is there anything you would like to do that your condition prevents you from doing?

\section{DATA ANALYSIS}

Raw data from the questionnaires were uploaded into Microsoft Excel datasheets. Data was cleaned according to the guidelines given by the IPAQ Research Committee. Continuous and Categorical Analyses of the cleaned date were done and presented as median METs/week and LPA.

Histograms were drawn up from the cleaned data by the Analysis ToolPak program to illustrate the results in a comparative manner. Datasheets were entered into the Stata-Statistical program 
for screening of missing values and range checked. The results from the Stat-program are presented in Table 2 as the Kruskal-Wallis scale.

Well-known qualitative data analysis methods were used that analyze the open-ended questions (Creswell 2003).

\section{RESULTS AND DISCUSSION}

The first objectives of the study were to determine the LPA of diabetes patients and to compare the LPA between male and female diabetes patients.

Sixty-five subjects ( 36 female and 29 male) participated in this study with ages ranging between 18 and 83 years. Three female participants were excluded from the scoring according to IPAQ guidelines: namely unreasonably high scores (Craig et al 2003). Table 1 illustrates the race, education level and type of diabetes of all the subjects.

A p-value of 0.3660 was calculated for the difference between the medians of the male's and female's LPA. This indicates a non-significant difference between the two genders.

Figure 1 illustrates the average physical activity of males and females in each domain, measured in METs. Data shows that the average METs per male was much higher for work-related activities than for females. The average METs per female for house and garden related activities on the other hand was higher than that of male subjects. This could be caused by the different gender-roles assigned to men and women by the society. Males work harder at their jobs, but females work harder at their homes. The male is seen as the breadwinner, thus the higher average at the work. The female's role is to look after the family and keep the house neat, thus, the higher average at the house. Similar findings were reported by Marshall et al(2007).

The next objective was to explore the reasons for possible differences on the LPA between the two genders.

In assessing a sample of 9806 adults (4140 men and 5666 women) Marshall and co-workers (2007) also reported little difference between gender in LPA, but more difference between racial groups.

Figure 2 shows the average physical activity per week in male and female subjects. To calculate these values the

Table 1: Sample description

\begin{tabular}{|l|l|l|l|}
\hline & Description & Male $(\mathbf{n m}=\mathbf{2 9})$ & Female $(\mathbf{n f}=\mathbf{3 3})$ \\
\hline Type of DM & 1 & 13 & 8 \\
\hline & 2 & 16 & 25 \\
\hline Ethnic group & Black & 6 & 12 \\
\hline & Colored & 1 & 0 \\
\hline & Indian & 4 & 2 \\
\hline & White & 18 & 19 \\
\hline Education level & None & 0 & 1 \\
\hline & Primary & 0 & 7 \\
\hline & Secondary & 22 & 23 \\
\hline & Tertiary & 7 & 2 \\
\hline
\end{tabular}

Table 2: Kruskal-Wallis non-parametic ANOVA

\begin{tabular}{|l|l|l|}
\hline Category & Gender $(\mathbf{n})$ & Median \\
\hline 1 & Female (10) & 356.25 \\
\hline 1 & Male (7) & 206 \\
\hline 2 & Female (9) & 1999.5 \\
\hline 2 & Male (9) & 1173 \\
\hline 3 & Female (14) & 6373.5 \\
\hline 3 & Male (13) & 8164 \\
\hline
\end{tabular}

Figure 1: Average METs per week in the four different domains.

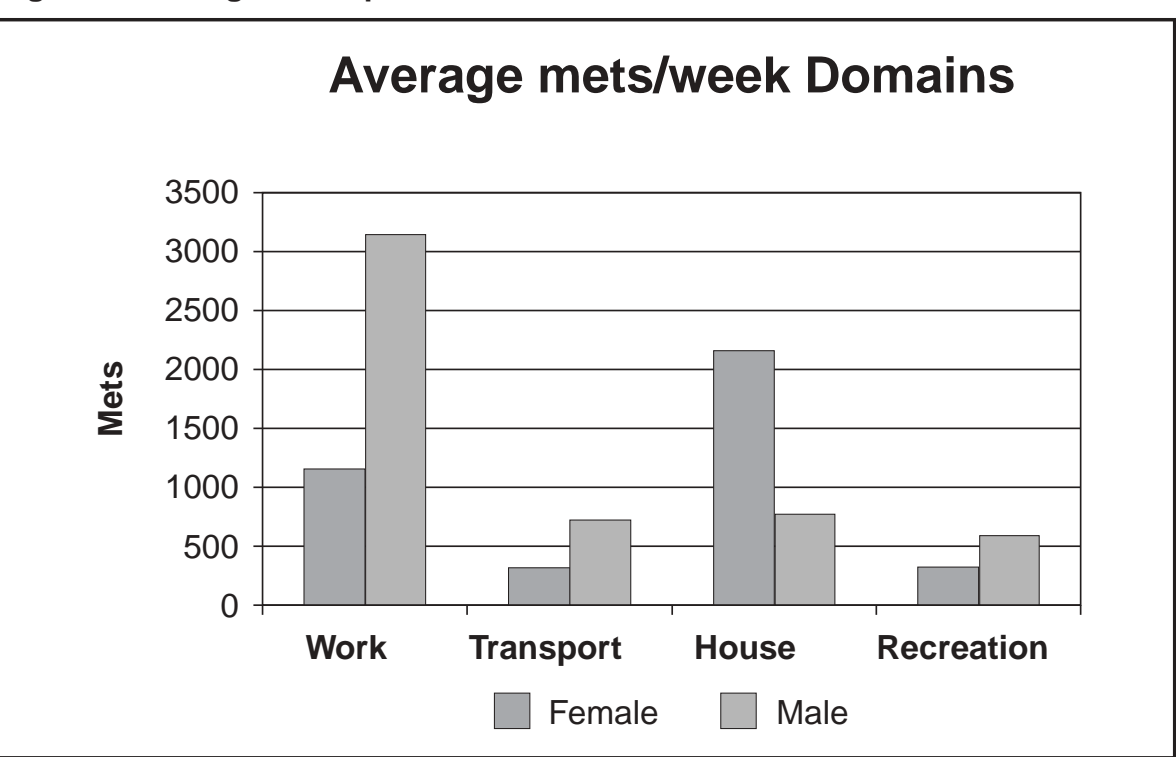

METs done by males in a week was divided by the number of males $(\mathrm{nm}=29)$. A similar calculation was performed for the female $(\mathrm{nf}=33)$. These values were used to classify the subjects into three categories (see Figure 3) according to the IPAQ research committee's guidelines (Craig et al 2003). Category 1, 2 and 3 resembles a low, moderate and high level of physical activity, respectively. According to figure 3 the largest group of subjects (14 female and 13 male subjects) fell into category 3 . This means that the largest part of the sample has a high level of physical activity, which may be unexpected. A possible reason for this is that habitual activity still resembles physical activity even though it is not commonly perceived as exercise. The IPAQ research 
Figure 2: Difference between male and female's average physical activity measured in METs.

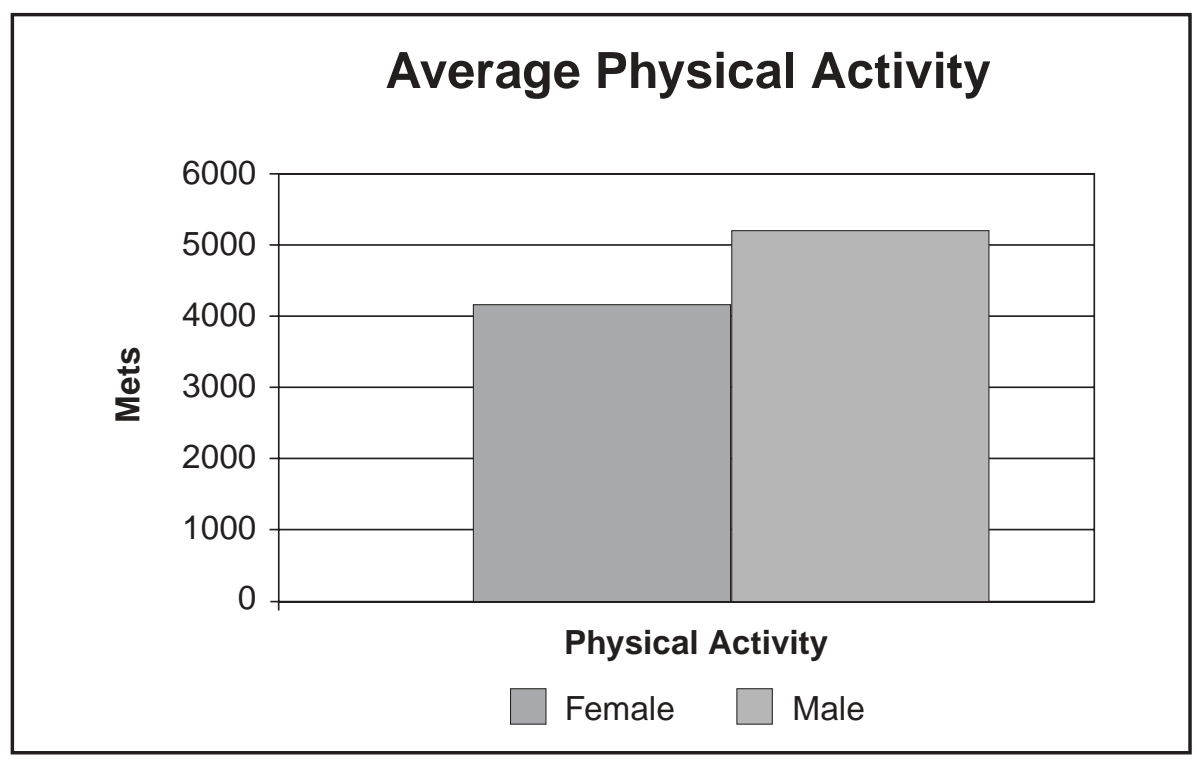

Figure 3: Categories of Physical Activity of males and females.

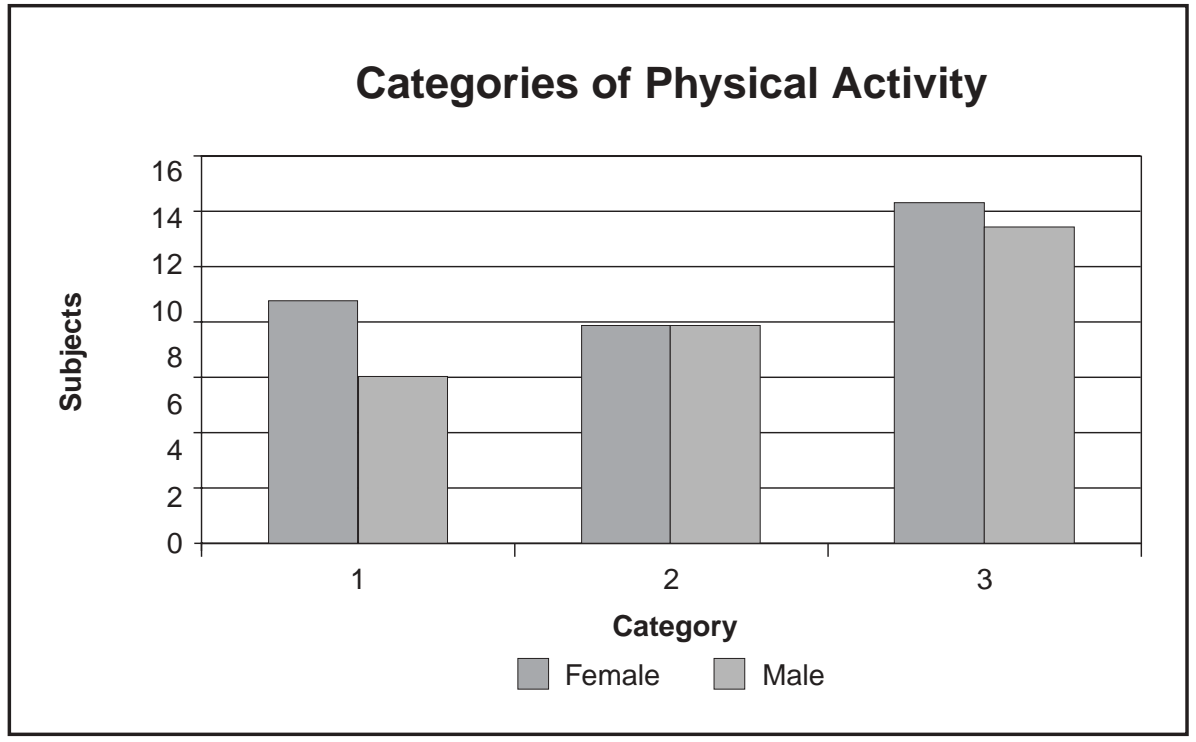

Figure 4: Barriers of physical activity.

\section{Barriers of Physical Activity}

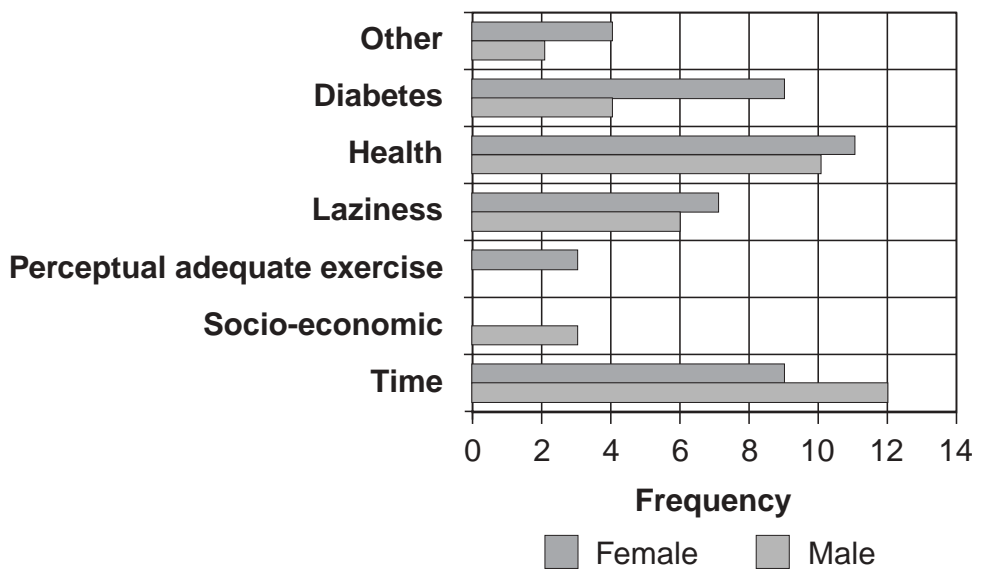

committee recommends that the levels of physical activity should be compared to different populations whereas in this study, males and females were compared in the same population (Craig et al 2003). Marshall and co-workers (2007) suggested that social class moderates the relationship between gender and leisure time inactivity rather than occupational physical therapy and that it should be taken into account when measuring physical activity. Furthermore, to really get an overview of the LPA of diabetes patients, the categories should be compared to those of non-diabetic patients.

Eighteen subjects - nine males and nine females - fell into category 2, which is a moderate level of physical activity. Di Loreto and co-workers (2005) showed that energy expenditure from 20 to 27 MET's per hour per week lead to increased health benefits.

Seven males and ten females fell into category 1, which is a low level of physical activity. Diabetes patients falling in this category should be advised on ways to increase their activity through daily activities. Examples are to take stairs instead of a lift, to clean the house and garden by themselves or to walk slightly faster while doing errands (Buse et al 2007). These lifestyle changes won't take a lot of extra time or effort but can contribute to a decrease in diabetes-related complications (The Look AHEAD Research Group, 2007)

The barriers were established by qualitative data analysis of the openended questionnaires and coded into seven categories namely: Diabetes, Health, Laziness, Perceptual adequate exercise, Socio-economic circumstances, Time and other. These findings are in line with the findings of Van Rooijen et al (2002) and are typical to the South African population. (Some of the categories included sub-divisions. "Diabetes" included different symptoms namely: decreased circulation, decreased blood sugar level, swollen feet, quick exhaustion, bad vision and amputations. "Health" included the following conditions: injury, breathlessness, arthritis, backache and heart conditions. The category named "Other" had sub-divisions such as being uninformed about exercise, caring for dependants, old age and 
cold weather. Bopape (2000) reported similar findings in her study on the beliefs and attitudes of patients with Type 2 Diabetes Mellitus in the Northern Province of South Africa.

Figure 4 contains the frequency of the occurrence of each barrier for males and females. For male subjects the three most frequent barriers were time (mentioned 12 times), health (mentioned 10 times) and laziness (mentioned 6 times). For females the three most frequently mentioned barriers were health (mentioned 11 times), time (mentioned 9 times) and diabetes complications (mentioned 9 times) (Creswell, 2003).

The overall LPA of diabetes patients is high according to the IPAQ Categorical scoring. Subjects were divided into three categories namely category 1,2 and 3 (low, moderate and high LPA respectively). The difference between LPA of males and females is not significant as indicated by the $p$-value $(p>0.05)$. It was however found that males have higher levels of work related activities than females and that females have higher home and garden related activities than males. The two most frequently mentioned barriers for male and female subjects were time and health related conditions. The third most common barrier for males was laziness and for females it was diabetes and/or its complications. Other barriers for physical activity were socio-economic circumstances, perceptual adequate exercise and other. These barrier have been reported by Van Rooijen et al (2002) in a similar population.

\section{RESEARCH RECOMMENDATIONS}

In a future study, the difference in age groups can be taken into consideration to have a more detailed description of LPA's in the different stages of life.

This sample only represents the Diabetes Clinic at Pretoria Academic Hospital and cannot be generalized to other broader settings.

A larger sample size would provide more accurate information, especially if it could be randomized. More research on the influence of social strata of the patients on physical activity should be conducted.

\section{CLINICAL RECOMMENDATION}

When exercises and educational information are given to diabetes patients, genders, social class strata and barriers preventing exercise should be taken into consideration in order to save them time and effort.

\section{ACKNOWLEDGEMENTS}

The researchers would like to acknowledge and thank the following individuals for their contribution to the study:

Prof. P. Rheeder

Mr. F. Grobler

\section{REFERENCES}

Amos AF, McCarty DJ and Zimmet P 1997 The rising global burden of diabetes and its complications, estimates and projections to the year 2010. Diabetes Medicin, 14: 1-85

Becker PJ and Kenneth L 2001 Principles and Practice of Endocrinology and Metabolism. pp 1341-1343. Lippincott Williams \& Wilkins

Bopape MW 2000 The beliefs and attidutes of patients with diabetes (non-insulin dependent) in the Nothern Province of South Africa (dissertation). University of the North: South Africa: 1-113

Bungard LB, Katzel LI, Busby-Whitehead MJ, Wu Z and Goldberg AP 2001 Energy requirements of middle-aged men are modifiable by physical activity. American Journal of Clinical Nutrition 68:1136-1142

Buse BB, Ginsberg HN, Bakris Gl, Clarke NG et al 2007 Primary prevention of cardiovascular diseases in people with Diabetes Mellitus. Diabetes Care 30: 162-73

Craig CL, Marshall AL and Sjöström M 2003 International physical activity questionnaire: 12-country reliability and validity. Medicine and Science and Sports Exercise 35: 1381-1395

Creswell JW 2003 Research Design. 2nd edn. Sage publications London

Delahanty LM 2002 Evidence-based trends for achieving weight loss and increased physical activity: applications for diabetes prevention and treatment. Diabetes Spectrum 15: $183-90$
Di Loreto C, Fanelli C, Lucidi P, Murdolo G et al 2005 Make your diabetes patients walk: long-term impact of different amounts of physical activity on type 2 diabetes. Diabetes Care 28: 1295-1302

McArdle WD, Katch FI and Katch VL 2000 Essentials of Exercise Physiology. 2nd edn. Williams and Wilkens, Lippencott

Motala AA, Omar MA and Pirie FJ 2003 Epidemiology of type 1 and type 2 diabetes in Africa. Journal of Cardiovascular Risk 10: 77-83

Seiler S 1996 Gender Differences in Endurance Performance and Training. http://home.hia.no/ stephens/gender.htm, $(07 / 02 / 06)$

The Look AHEAD Research Group 2007 Reduction in weight and cardiovascular disease risk factors in individuals with Type 2 Diabetes. Diabetes Care 30: 1374-1383

Van Rooijen AJ, Rheeder p, Eales CJ, Molatoli HM 2002 Barriers to and expectations of performing physical activity in female patients with Type 2 Diabetes Mellitus. South African Journal of Physiotherapy 57: 3-11

Van Rooijen AJ, Rheeder P, Eales CJ, Becker PJ 2003 Black female patients with type 2 diabetes mellitus: knowledge, attitudes and physical activity. South African Journal of Physiotherapy 57: 20-27

www.ipaq.ki.se, 2006, 17/02/2006 